\title{
Minimum inhibitory concentration of carbapenems and tigecycline against Salmonella spp.
}

\section{Correspondence \\ Deepthi Nair \\ deepthinair2@gmail.com}

Received 31 December 2007

Accepted 31 October 2008

\author{
Malini R. Capoor, ${ }^{1}$ Deepthi Nair, ${ }^{1}$ Jitendra Posti, ${ }^{1}$ Smita Singhal, ${ }^{2}$ \\ Monorama Deb, ${ }^{1}$ Pushpa Aggarwal ${ }^{1}$ and Parukutty Pillai ${ }^{3}$
}

\author{
${ }^{1}$ Department of Microbiology, Vardhman Mahavir Medical College and Safdarjung Hospital, New \\ Delhi, India \\ ${ }^{2}$ New Drug Discovery, Ranbaxy Research Laboratories, Gurgaon, India \\ ${ }^{3}$ Department of Microbiology, Majeedia Hospital, Hamdard University, New Delhi, India
}

\begin{abstract}
Antimicrobial resistance in Salmonella spp. is of grave concern, more so in quinolone-resistant and extended-spectrum $\beta$-lactamase (ESBL)-producing isolates that cause complicated infections. The MIC of azithromycin, ciprofloxacin, cefixime, cefepime, ceftriaxone, gatifloxacin, imipenem, levofloxacin, meropenem and ofloxacin (E-test strip) and tigecycline and faropenem (agar dilution) against 210 Salmonella spp. was determined. MIC $_{90}$ (defined as the antimicrobial concentration that inhibited growth of $90 \%$ of the strains) of the carbapenems (imipenem and meropenem) for Salmonella Typhi and Salmonella Paratyphi A was $0.064 \mu \mathrm{g} \mathrm{ml}^{-1}$. $\mathrm{MIC}_{90}$ of faropenem was $0.25 \mathrm{mg} \mathrm{ml}^{-1}$ for S. Typhi, S. Paratyphi A and Salmonella Typhimurium. The $\mathrm{MIC}_{90}$ of azithromycin for all Salmonella spp. ranged from 8 to $16 \mu \mathrm{g} \mathrm{ml}^{-1}$. Tigecycline showed an $\mathrm{MIC}_{90}$ of $2 \mu \mathrm{g} \mathrm{ml}^{-1}$ for $S$. Typhi, $1 \mu \mathrm{g} \mathrm{ml}^{-1}$ for $S$. Paratyphi $A$ and $4 \mu \mathrm{g} \mathrm{m}^{-1}$ for $S$.

Typhimurium. We concluded that tigecycline and the carbapenems are likely to have roles in the final stage of treatment of quinolone-resistant and ESBL-producing multidrug-resistant salmonellae.
\end{abstract}

\section{INTRODUCTION}

Nalidixic acid-resistant (NAR) Salmonella causing enteric fever are now also found to be ciprofloxacin resistant; this has necessitated the search for novel antimicrobials. Options available for treatment of enteric fever include newer quinolones, extended-spectrum cephalosporins and azithromycin (Cooke et al., 2006; Kownhar et al., 2007; Parry et al., 2007). A large number of current and previous studies question the efficacy of newer quinolones in treating enteric fever caused by ciprofloxacin-resistant Salmonella (Harish et al., 2006; Joshi \& Amarnath, 2007). A rise in the MIC of third and fourth generation cephalosporins for Salmonella spp. has been observed recently (Capoor et al., 2006; Saha et al., 1999).

A number of studies have observed a rise in the MIC of azithromycin. Despite its intracellular concentration and clinical efficacy, it cannot be used in routine treatment of enteric fever due to a lack of large-scale in vivo and in vitro

Abbreviations: CLSI, Clinical and Laboratory Standards Institute; ESBL, extended-spectrum $\beta$-lactamase; EUCAST, European committee on antimicrobial susceptibility testing; FDA, Food and Drug Administration; $\mathrm{MDR}$, multidrug-resistant; $\mathrm{MIC}_{50}$ and $\mathrm{MIC}_{90}$, antimicrobial concentration that inhibited growth of 50 and $90 \%$, respectively, of the strains; NAR, nalidixic acid-resistant. studies (Capoor et al., 2007; Frenck et al., 2004; Girgis et al., 1999; Parry et al., 2007).

The roles of newer classes of antimicrobials, such as glycylcyclines and carbapenems, against salmonellae need to be elucidated. Tigecycline is a glycylcycline (tetracycline analogue), it inhibits protein synthesis and evades efflux and target-mediated resistance seen against classical tetracyclines (Livermore, 2005; Fritsche et al., 2005). The carbapenems are a class of $\beta$-lactam antibiotics with broadspectrum activity and are stable to hydrolysis by extendedspectrum $\beta$-lactamase (ESBL)-producing isolates (Sorbera et al., 2002). Though the use of carbapenems is not recommended (CLSI, 2006), it may become crucial, especially when treating ESBL-producing salmonellae causing enteric fever (Pokharel et al., 2006). Moreover, with an increase in the incidence of unusual and complicated paratyphoid fever (Harish et al., 2006) and non-typhoidal salmonellae causing septicaemia (Egorova et al., 2007; Sun et al., 2005), the development of newer broad-spectrum antimicrobials needs to be explored.

The current study was carried out to assess the MIC of the currently available and novel antimicrobials for salmonellae isolates from a region that is endemic for NAR strains and is currently facing ciprofloxacin resistance in salmonellae that cause enteric fever. 


\section{METHODS}

The current study was conducted on Salmonella isolates recovered from enteric fever and septicaemia cases at Vardhman Mahaveer Medical College, Safdarjung Hospital (a tertiary care centre) and Majeedia Hospital (a private referral hospital) in New Delhi, India, over a period of 2 years (2006-2007). Blood for culture was collected prior to initiation of antimicrobial therapy using aseptic procedures, and was processed using standard microbiological protocols (Old, 1996). Salmonella spp. were identified using standard biochemical tests (Old, 1996) and confirmed by detection with specific antisera (Central Research Institute, Kasauli, India).

A total of 479 isolates of Salmonella spp. were recovered from 38282 blood cultures. Of these, 210 isolates were randomly selected for the study. Antimicrobial susceptibility testing of the isolates was carried out by the standard Kirby Bauer disk-diffusion method using Clinical and Laboratory Standards Institute (CLSI) guidelines (CLSI, 2006). The following antimicrobials were used: ampicillin $\left(10 \mu \mathrm{g} \mathrm{ml}^{-1}\right)$, chloramphenicol $\left(30 \mu \mathrm{g} \mathrm{ml}^{-1}\right)$, co-trimoxazole $\left(1.25 / 23.75 \mu \mathrm{g} \mathrm{ml}^{-1}\right)$, ceftriaxone $\left(30 \mu \mathrm{g} \mathrm{ml}^{-1}\right)$, cefixime $\left(5 \mu \mathrm{g} \mathrm{ml}^{-1}\right)$, ciprofloxacin $\left(5 \mu \mathrm{g} \mathrm{ml}^{-1}\right)$ and nalidixic acid $\left(30 \mu \mathrm{g} \mathrm{ml}^{-1}\right)$. Isolates resistant to ampicillin, chloramphenicol and co-trimoxazole were defined as multidrug-resistant (MDR).

The MIC of azithromycin, ciprofloxacin, cefixime, cefepime, ceftriaxone, gatifloxacin, imipenem, levofloxacin, meropenem and ofloxacin for the 210 Salmonella isolates was determined by using Etest strips (AB Biodisk). The results were interpreted according to the CLSI guidelines (CLSI, 2006). The MIC of tigecycline and faropenem (Ranbaxy laboratories, Gurgaon, India) for Salmonella isolates was determined by agar dilution on cation-adjusted Mueller-Hinton agar. Isolates with intermediate levels of resistance were included in the percentage of resistant organisms for final analysis. Escherichia coli ATCC 25922 was used as a control strain.

The breakpoint MIC levels for azithromycin, tigecycline and faropenem for isolates of Salmonella spp. have not been determined. However, for the current study, breakpoints for faropenem and azithromycin that were determined in previous in vitro studies were used (Piddock et al., 2003; Girgis et al., 1999). For tigecycline, the Food and Drug Administration (FDA)-approved susceptibility test result interpretative criteria were used (Brown \& Traczewski, 2007). These are defined as sensitive, $\leqslant 2 \mu \mathrm{g} \mathrm{ml}^{-1}$; intermediate, $4 \mu \mathrm{g} \mathrm{ml}^{-1}$; resistant, $\geqslant 8 \mu \mathrm{g} \mathrm{ml}^{-1}$.

The Salmonella isolates were screened for the presence of ESBL production by using the double disk diffusion method using ceftazidime $\left(30 \mu \mathrm{g} \mathrm{ml}^{-1}\right)$, cefoperazone $\left(75 \mu \mathrm{g} \mathrm{ml}^{-1}\right)$, ceftriaxone $\left(30 \mu \mathrm{g} \mathrm{ml}^{-1}\right)$ and cefotaxime $\left(30 \mu \mathrm{g} \mathrm{ml}^{-1}\right)$. Presence of ESBL was confirmed by using combination E-test strips containing cefotaxime and cefotaxime-clavulanic acid or cefepime and cefepime-clavulanic acid. A threefold or more fall in MIC in the presence of clavulanic acid was considered to be indicative of ESBL production.

\section{RESULTS AND DISCUSSION}

Of the 210 isolates recovered from blood cultures from suspected cases of enteric fever and septicaemia, Salmonella Typhi was the predominant serotype (149, 70.95\%), followed by Salmonella Paratyphi A (43, 20.47\%) and Salmonella Typhimurium (17, 8.1\%); one Salmonella Enteritidis isolate was identified. Multidrug resistance was seen in $S$. Typhi $(6,4 \%), S$. Paratyphi A $(2,4.6 \%)$ and $S$. Typhimurium $(8,47 \%)$ but not in $S$. Enteritidis $(0,0 \%)$. NAR isolates of $S$. Typhi $(142,95.3 \%), S$. Paratyphi A (40, $93 \%)$ and $S$. Typhimurium $(6,35.3 \%)$ were detected.

Tables 1, 2 and 3 depict the MICs of various antimicrobials for S. Typhi, S. Paratyphi A and S. Typhimurium, respectively.

For the quinolones that were tested (ciprofloxacin, gatifloxacin, levofloxacin and ofloxacin), the antimicrobial

Table 1. MIC of various antimicrobials for S. Typhi

The number of strains for each MIC is shown. -, No growth.

The CLSI (2006) interpretive criteria for sensitive, intermediate and resistant strains, respectively, are $\left(\mu \mathrm{g} \mathrm{ml}^{-1}\right)$ : ciprofloxacin $(\mathrm{Cf}), \leqslant 1,2, \geqslant 4$; levofloxacin (Le), ofloxacin (Of) and gatifloxacin (Ga), $\leqslant 2,4, \geqslant 8$; imipenem (I) and meropenem (M), $\leqslant 4,8, \geqslant 16$; faropenem (F) and azithromycin $(\mathrm{Az})$, breakpoints analysed by prior in vitro studies indicated $\geqslant 32=$ resistant (Piddock et al., 2003; Girgis et al., 1999); ceftriaxone $(\mathrm{Ci}), \leqslant 8,16-32, \geqslant 64$; cefixime $(\mathrm{Cfx}), \leqslant 1,2, \geqslant 4$; cefepime $(\mathrm{Cpm}), \leqslant 8,16, \geqslant 32$; tigecycline $(\mathrm{Ti}), \leqslant 2,4, \geqslant 8$.

\begin{tabular}{|c|c|c|c|c|c|c|c|c|c|c|c|c|}
\hline $\begin{array}{l}\text { MIC } \\
\left(\mu \mathrm{ml}^{-1}\right)\end{array}$ & Cf & Le & Of & Ga & I & M & F & $\mathbf{A z}$ & $\mathrm{Ci}$ & Cfx & Cpm & $\mathrm{Ti}$ \\
\hline$\leqslant 0.032$ & 3 & 8 & 1 & 7 & 108 & 110 & 111 & 2 & 14 & 18 & 35 & 5 \\
\hline 0.064 & 2 & 4 & 1 & 5 & 24 & 28 & 13 & 3 & 19 & 20 & 20 & 10 \\
\hline 0.125 & 22 & 15 & 7 & 20 & $12^{*}$ & 9 & 9 & 4 & 75 & 53 & 56 & 1 \\
\hline 0.25 & 44 & 45 & 41 & 30 & 5 & 2 & $15^{*}$ & 2 & 25 & 39 & $23^{*}$ & 49 \\
\hline 0.5 & 23 & 24 & 31 & 20 & - & - & 1 & 8 & $7^{*}$ & $8^{*}$ & 5 & 45 \\
\hline 1 & 14 & 10 & 27 & 24 & - & - & - & 19 & 3 & 8 & - & 21 \\
\hline 2 & 2 & 6 & 4 & 13 & - & - & - & 31 & 4 & 1 & - & $14^{*}$ \\
\hline 4 & 1 & 4 & 2 & 7 & - & - & - & 30 & 1 & 1 & - & 4 \\
\hline 8 & 6 & 6 & 3 & 8 & - & - & - & $35^{*}$ & - & - & - & - \\
\hline 16 & 2 & 2 & - & $15^{*}$ & - & - & - & 14 & - & - & - & - \\
\hline$\geqslant 32$ & $30^{*}$ & $25^{*}$ & $32^{*}$ & - & - & - & - & 1 & 1 & 1 & 1 & - \\
\hline Total & 149 & 149 & 149 & 149 & 149 & 149 & 149 & 149 & 149 & 149 & 149 & 149 \\
\hline
\end{tabular}

${ }^{\star}$ Indicates $\mathrm{MIC}_{90}$ values. 
Table 2. MIC of various antimicrobials for $S$. Paratyphi $A$

The number of strains for each MIC is shown. -, No growth.

For CLSI interpretive criteria see Table 1.

\begin{tabular}{|c|c|c|c|c|c|c|c|c|c|c|c|c|}
\hline $\begin{array}{l}\text { MIC } \\
\left(\mu \mathrm{g} \mathrm{ml}^{-1}\right)\end{array}$ & Cf & Le & Of & $\mathrm{Ga}$ & I & $\mathbf{M}$ & F & $\mathrm{Az}$ & $\mathbf{C i}$ & Cfx & Cpm & $\mathrm{Ti}$ \\
\hline$\leqslant 0.032$ & 4 & 4 & 0 & 1 & 32 & 34 & 25 & 0 & 3 & 1 & 2 & 1 \\
\hline 0.125 & 3 & 1 & 2 & 2 & 2 & 3 & 3 & 1 & 15 & 13 & 15 & 2 \\
\hline 0.25 & 10 & 12 & 4 & 4 & 1 & 1 & $5^{\star}$ & 1 & 11 & 14 & $15^{\star}$ & 15 \\
\hline 0.5 & 9 & 13 & 6 & 9 & - & - & - & - & $5^{\star}$ & $6^{*}$ & 1 & 13 \\
\hline 2 & - & 1 & $4^{*}$ & $2^{\star}$ & - & - & - & 9 & 1 & - & 1 & 4 \\
\hline 4 & $1^{\star}$ & - & - & 2 & - & - & - & 8 & - & - & - & - \\
\hline 8 & - & - & - & - & - & - & - & 14 & - & - & - & - \\
\hline 6 & - & - & - & - & - & - & - & $4^{*}$ & - & - & - & - \\
\hline$\geqslant 32$ & 5 & 4 & 4 & 3 & - & - & - & 1 & - & - & - & - \\
\hline Total & 43 & 43 & 43 & 43 & 43 & 43 & 43 & 43 & 43 & 43 & 43 & 43 \\
\hline
\end{tabular}

${ }^{\star}$ Indicates $\mathrm{MIC}_{90}$ values.

concentration that inhibited growth of $90 \%$ of the strains $\left(\mathrm{MIC}_{90}\right)$ ranged from $16 \mu \mathrm{g}$ gatifloxacin $\mathrm{ml}^{-1}$ to $32 \mu \mathrm{g} \mathrm{ml}^{-1}$ for the other quinolones for $S$. Typhi. For $S$. Paratyphi A, the $\mathrm{MIC}_{90}$ of ciprofloxacin and levofloxacin was $1 \mu \mathrm{g} \mathrm{ml}^{-1}$ and was $2 \mu \mathrm{g} \mathrm{ml}^{-1}$ for ofloxacin and gatifloxacin. The $\mathrm{MIC}_{90}$ of all the quinolones for $S$. Typhimurium was in the susceptible range. For the cephalosporins tested (cefixime, cefepime and ceftriaxome), the lowest $\mathrm{MIC}_{90}$ was $0.25 \mu \mathrm{g} \mathrm{ml}^{-1}$ of cefepime for $S$. Typhi and $S$. Paratyphi A. A single $S$. Typhi isolate $(0.67 \%)$ and 16 S. Typhimurium isolates (94.1\%) were
ESBL producers. The $\mathrm{MIC}_{90}$ of all cephalosporins for $S$. Typhimurium was $\geqslant 32 \mu \mathrm{g} \mathrm{ml}^{-1}$.

The $\mathrm{MIC}_{90}$ of the carbapenems (imipenem and meropenem) for $S$. Typhi and $S$. Paratyphi A was $0.064 \mu \mathrm{g} \mathrm{ml}^{-1}$. The $\mathrm{MIC}_{90}$ of faropenem for S. Typhi, S. Paratyphi A and $S$. Typhimurium was $0.25 \mu \mathrm{g} \mathrm{ml}^{-1}$. The $\mathrm{MIC}_{90}$ of azithromycin for $S$. Typhi, S. Paratyphi A and $S$. Typhimurium was 8, 16 and $8 \mu \mathrm{g} \mathrm{ml}^{-1}$, respectively. Tigecycline displayed an $\mathrm{MIC}_{90}$ at $2 \mu \mathrm{g} \mathrm{ml}^{-1}$ for S. Typhi, $1 \mu \mathrm{g} \mathrm{ml}^{-1}$ for $S$. Paratyphi A and $4 \mu \mathrm{g} \mathrm{ml}^{-1}$ for $S$. Typhimurium.

Table 3. MIC of various antimicrobials for $S$. Typhimurium

The number of strains for each MIC is shown. -, No growth.

For CLSI interpretive criteria see Table 1.

\begin{tabular}{|c|c|c|c|c|c|c|c|c|c|c|c|c|}
\hline $\begin{array}{l}\text { MIC } \\
\left(\mu \mathrm{g} \mathrm{ml}^{-1}\right)\end{array}$ & Cf & Le & Of & $\mathbf{G a}$ & I & M & F & $\mathrm{Az}$ & $\mathrm{Ci}$ & Cfx & Cpm & $\mathrm{Ti}$ \\
\hline$\leqslant 0.032$ & 13 & 7 & 2 & 12 & 1 & 1 & 1 & 2 & 0 & 0 & 0 & 0 \\
\hline 0.125 & 1 & 1 & 7 & 2 & $8^{*}$ & $8^{*}$ & 6 & 0 & 0 & 0 & 0 & 0 \\
\hline 0.25 & $2^{*}$ & 0 & 2 & $13^{*}$ & - & - & $4^{\star}$ & 0 & 0 & 0 & 0 & 0 \\
\hline 0.5 & 1 & $2^{*}$ & 0 & - & - & - & - & 0 & 0 & 0 & 0 & 0 \\
\hline 2 & - & - & - & - & - & - & - & 3 & 0 & 0 & 2 & 6 \\
\hline 4 & - & - & - & - & - & - & - & 5 & 0 & 0 & 5 & $8^{*}$ \\
\hline 8 & - & - & - & - & - & - & - & $2^{*}$ & 8 & 8 & 1 & 1 \\
\hline 16 & - & - & - & - & - & - & - & 1 & 2 & 2 & 1 & - \\
\hline$\geqslant 32$ & - & - & - & - & - & - & - & 1 & $7^{\star}$ & $7^{\star}$ & - & - \\
\hline Total & 17 & 17 & 17 & 17 & 17 & 17 & 17 & 17 & 17 & 17 & 17 & 17 \\
\hline
\end{tabular}

${ }^{*}$ Indicates $\mathrm{MIC}_{90}$ values. 
The MICs of quinolones, cephalosporins, carbapenems, azithromycin and tigecycline for $S$. Enteritidis were in the sensitive range.

Amongst the fluoroquinolones tested, the $\mathrm{MIC}_{90}$ of gatifloxacin ( $\mathrm{MIC}_{90} 16 \mu \mathrm{g} \mathrm{ml}^{-1}$ ) was marginally lower compared with the $\mathrm{MIC}_{90}$ of other quinolones $\left(\mathrm{MIC}_{90}\right.$ $\geqslant 32 \mu \mathrm{g} \mathrm{ml}^{-1}$ ) for $S$. Typhi. The $\mathrm{MIC}_{90}$ of gatifloxacin for $S$. Paratyphi A was $2 \mu \mathrm{g} \mathrm{ml}^{-1}$ and was $1 \mu \mathrm{g} \mathrm{ml}^{-1}$ for other quinolones. Nonetheless, the antimicrobial concentration that inhibited growth of $50 \%$ of the strains $\left(\mathrm{MIC}_{50}\right)$ of all quinolones for $S$. Typhi and $S$. Paratyphi A was $0.5 \mu \mathrm{g} \mathrm{ml}^{-1}$ and $0.5-1 \mu \mathrm{g} \mathrm{ml}^{-1}$, respectively. In contrast, the $\mathrm{MIC}_{50}$ and $\mathrm{MIC}_{90}$ of all quinolones for $S$. Typhimurium were in the susceptible range. The resistant MICs seen for the majority of isolates in this study have also been observed in prior studies (Capoor et al., 2007; Cooke et al., 2006; Joshi \& Amarnath, 2007; Kownhar et al., 2007). Thus, the higher (resistant) MICs suggest that quinolones should be withdrawn from use in treatment of enteric fever and that their use should be restricted to septicaemia cases caused by other salmonellae. Quinolones should not be used in the therapy of patients infected with NAR isolates as these are associated with therapeutic failures, despite their decreased susceptibility (0.125$1 \mu \mathrm{g} \mathrm{ml}^{-1}$ ) to ciprofloxacin and other quinolones (Capoor et al., 2006; Cooke et al., 2006; Kownhar et al., 2007).

Cefepime had the lowest $\mathrm{MIC}_{90}$, at $0.25 \mu \mathrm{g} \mathrm{ml}{ }^{-1}$, for $S$. Typhi and S. Paratyphi A. This may be attributed to its parenteral route of administration, making it less effective than cefixime. Only a single isolate of $S$. Typhi was an ESBL producer and had a high MIC for cephalosporins (resistant phenotype). Until now, there have been few reports of ESBL producers in S. Typhi and S. Paratyphi A strains (Pokharel et al., 2006). Overuse of cephalosporins in ciprofloxacin-resistant salmonellae causing enteric fever has selected for the production of ESBL-producing isolates. In stark contrast to ESBL production in $S$. Typhi, there are many reports of ESBL-producing $S$. Typhimurium in the literature (Egorova et al., 2007; Weill et al., 2006; AitMhand et al., 2002; Otkun et al., 2001). This was also observed in our study, as $94.1 \%$ of the $S$. Typhimurium isolates were ESBL producers. Frequent production of ESBL in $S$. Typhimurium is attributable to plasmidmediated class A ESBLs belonging to the TEM, SHV and CTX-M or PER CMY family (Weill et al., 2006). As this type of resistance is commonly transferred by these isolates to other bacteria, the transfer to $S$. Typhi and $S$. Paratyphi $\mathrm{A}$ is a major risk.

The MIC $_{90}$ values of azithromycin for $S$. Typhi, $S$. Paratyphi A and $S$. Typhimurium were 8,16 and $8 \mu \mathrm{g} \mathrm{ml} \mathrm{m}^{-1}$, respectively. In a prior study on ciprofloxacin-resistant $S$. Typhi and S. Paratyphi A (Capoor et al., 2007), the $\mathrm{MIC}_{90}$ was $24 \mu \mathrm{g} \mathrm{ml}^{-1}$. The high $\mathrm{MIC}_{90}$ may have been due to the fact that this study was performed using ciprofloxacin-resistant isolates only. In contrast, isolates were randomly selected in the current study and there was no selection bias for quinolone-resistant isolates. A rise in the MIC of azithromycin was predicted (Girgis et al., 1999; Butler et al., 1999; Frenck et al., 2004; Capoor et al., 2007) because of its injudicious out-patient use. Nonetheless, keeping in mind its intracellular concentration, large-scale randomized clinical trials are warranted to determine the correlation between in vivo and in vitro studies.

In this study, the $\mathrm{MIC}_{90}$ of the penems (imipenem and meropenem) for $S$. Typhi and $S$. Paratyphi A $\left(0.064 \mu \mathrm{g} \mathrm{ml}^{-1}\right)$ was lower compared with that for $S$. Typhimurium $\left(0.125 \mu \mathrm{g} \mathrm{ml}^{-1}\right)$. Overall, faropenem had a high $\mathrm{MIC}_{90}\left(0.25 \mu \mathrm{g} \mathrm{ml}^{-1}\right)$ for $S$. Typhi, S. Paratyphi A and $S$. Typhimurium compared with the other penems. Previous reports (Piddock et al., 2003; Sun et al., 2005) also observed that faropenem was less active than imipenem, where the $\mathrm{MIC}_{90}$ for salmonellae was reported as 0.5$1 \mu \mathrm{g} \mathrm{ml}^{-1}$. Penems are a class of $\beta$-lactam antibiotic which possess potent broad-spectrum activity and are extremely stable against ESBLs (Sorbera et al., 2002).

Against our collection of isolates, tigecycline was very potent, inhibiting $97.3 \%$ of $S$. Typhi, as well as $100 \%$ of $S$. Paratyphi A and S. Enteritidis. This is in agreement with the European committee on antimicrobial susceptibility testing (EUCAST) data and a prior study conducted on a large group of Salmonella isolates [European Committee on Antimicrobial Susceptibility Testing (EUCAST) Steering Committee, 2006; Morosini et al., 2006; Brown \& Traczewski, 2007]. Only $55.5 \%$ of $S$. Typhimurium isolates were in the sensitive range for tigecycline. It should be noted, however, that the $\mathrm{MIC}_{90}$ for $S$. Typhimurium isolates $\left(4 \mu \mathrm{g} \mathrm{ml}^{-1}\right)$ was higher than that for the other species tested, and it was at the breakpoint of susceptibility, as approved by the FDA. The findings of our study are consistent with those of EUCAST.

In vivo and in vitro studies have demonstrated that acquired resistance to tigecycline is associated with upregulation of a chromosomally mediated efflux pump (Livermore, 2005; Brown \& Traczewski, 2007 ). Tigecycline lacks crossresistance with other compounds and it could aid in the therapy of MDR salmonelloses. Resistance to or a high MIC of tigecycline was rare in our collection of Salmonella isolates showing resistance to or high MIC of quinolones. Furthermore, tigecycline was also active against ceftriaxone-resistant Salmonella isolates. Nevertheless, systematic large-scale in vivo studies are needed to assess the relative merits of tigecycline versus other antimicrobials in the treatment of these infections. Unfortunately, owing to presence of the $\beta$-lactam ring, strains resistant to the penems show cross-resistance to other antimicrobials.

Enteric fever caused by ciprofloxacin-resistant salmonellae is found uniquely in countries of the Indian subcontinent. In India, this may be attributed to misuse of ciprofloxacin due to administration via the oral route, affordability, over-the-counter availability and its spurious quality 
(Capoor et al., 2006). The observations of this study imply that tigecycline and the penems represent a reserve of antimicrobials that have therapeutic potential for the treatment of ESBL-producing MDR salmonellae in the future. Clinical efficacy trials are warranted to reach a conclusion in this regard.

\section{REFERENCES}

AitMhand, R., Soukri, A., Moustaoui, N., Amarouch, H., ElMdaghri, N., Sirot, D. \& Benbachir, M. (2002). Plasmid-mediated TEM-3 extendedspectrum $\beta$-lactamase production in Salmonella typhimurium in Casablanca. J Antimicrob Chemother 49, 169-172.

Brown, S. D. \& Traczewski, M. M. (2007). Comparative in vitro antimicrobial activity of tigecycline, a new glycylcycline compound, in freshly prepared medium and quality control. J Clin Microbiol 45, 2173-2179.

Butler, T., Sirdhar, C. B., Daga, M. K., Pathak, K., Pandit, R. B., Khakhria, R., Potkar, C. N. \& Zelasky, M. T. (1999). Treatment of typhoid fever with azithromycin vs chloramphenicol in a randomized multicentre trial in India. J Antimicrob Chemother 44, 243-250.

Capoor, M. R., Nair, D., Hasan, A. S., Aggarwal, P. \& Gupta, B. (2006). Narrowing therapeutic options in typhoid fever, India. Southeast Asian J Trop Med Public Health 37, 1170-1174.

Capoor, M. R., Rawat, D., Nair, D., Hasan, A. S., Deb, M., Aggarwal, P. \& Pillai, P. K. (2007). In vitro activity of azithromycin, newer quinolones and cephalosporins in ciprofloxacin-resistant Salmonella causing enteric fever. J Med Microbiol 56, 1490-1494.

CLSI (2006). Performance Standards for Antimicrobial Susceptibility Testing, 17th Informational Supplement. CLSI Document M100-S16, 26. Wayne, PA: CLSI.

Cooke, F. J., Wain, J. \& Threlfall, E. J. (2006). Fluoroquinolone resistance in Salmonella enterica serovar Typhi. BMJ 333, 353-354.

Egorova, S., Kaftyreva, L., Grimont, P. A. D. \& Weill, F. X. (2007). Prevalence and characterization of extended-spectrum cephalosporinresistant nontyphoidal Salmonellae isolates in adults in Saint Petersburg, Russia (2002-2005). Microb Drug Resist 13, 102-107.

European Committee on Antimicrobial Susceptibility Testing (EUCAST) Steering Committee (2006). EUCAST technical note on tigecycline Clin Microbiol Infect 12, 1147-1149.

Frenck, R. W., Jr, Mansour, A., Nakhla, I., Sultan, Y., Putnam, S., Wierzba, T., Morsy, M. \& Knirsch, C. (2004). Short course azithromycin for the treatment of uncomplicated typhoid fever in children and adolescents. Clin Infect Dis 38, 951-957.

Fritsche, T. R., Strabala, P. A., Sader, H. S., Dowzicky, M. J. \& Jones, R. N. (2005). Activity of tigecycline tested against a global collection of Enterobacteriaceae including tetracycline-resistant isolates. Diagn Microbiol Infect Dis 52, 209-213.

Girgis, N. I., Butler, T., Frenck, R. W., Sultan, Y., Brown, F. M., Tribble, D., Johnson, R. B. \& Khakhria, R. (1999). Azithromycin versus ciprofloxacin for treatment of uncomplicated typhoid fever in a randomized trial in Egypt that included patients with multidrug resistance. Antimicrob Agents Chemother 43, 1441-1444.

Harish, B. N., Menezes, G. A., Sarangapani, K. \& Parija, S. C. (2006). Fluoroquinolone resistance among Salmonella enterica serovar Paratyphi A in Pondicherry. Indian J Med Res 124, 585-587.

Joshi, S. \& Amarnath, S. K. (2007). Fluoroquinolone resistance in $S$. Typhi and S. Paratyphi A in Banglore, India. Trans R Soc Trop Med Hyg 101, 308-310.

Kownhar, H., Shankar, E. M., Rajan, R. \& Rao, U. A. (2007). Emergence of nalidixic acid-resistant Salmonella enterica serovar Typhi resistant to ciprofloxacin in India. J Med Microbiol 56, 136-137.

Livermore, D. M. (2005). Tigecycline: What is it, and where should it be used? J Antimicrob Chemother 56, 611-614.

Morosini, M. I., Garcia-Castillo, M., Coque, T. M., Valverde, A., Novais, A., Loza, E., Baquero, F. \& Canton, F. (2006). Antibiotic coresistance in extended spectrum- $\beta$-lactamase producing Enterobacteriaceae and in vitro activity of tigecycline. Antimicrob Agents Chemother 50, 2695-2699.

Old, D. C. (1996). Salmonella. In Mackie and McCartney Practical Medical Microbiology, 14th edn, pp. 385-404. Edited by J. G. Collee, A. G. Fraser, B. P. Marmion \& A. Simmons. Edinburgh: Churchill Livingstone.

Otkun, M., Erdem, B., Akata, F., Tatman-Otkun, M., Gerceker, D., Yagci, S. \& Ozkan, E. (2001). Antibiotic resistance patterns and plasmid profiles of Salmonella typhimurium isolates in Turkey. Eur J Clin Microbiol Infect Dis 20, 206-209.

Parry, C. M., Ho, V. A., Phuong, L. T., Bay, P. V., Lanh, M. N., Tung, L. T., Tham, N. T., Wain, J. \& Hien, T. T. (2007). A randomized controlled comparison of ofloxacin, azithromycin and ofloxacin-azithromycin combination for treatment of multidrug-resistant and nalidixic acidresistant typhoid fever. Antimicrob Agents Chemother 51, 819-825.

Piddock, L. J. V., Johnson, M. M. \& Webber, M. A. (2003). Activity of faropenem and imipenem for ciprofloxacin-resistant bacteria. J Antimicrob Chemother 52, 500-502.

Pokharel, B. M., Koirala, J., Dahal, R. K., Mishra, S. K., Khadga, P. K. \& Tuladhar, N. R. (2006). Multidrug-resistant and extended-spectrum $\beta$-lactamase (ESBL)-producing Salmonella enterica (serotypes Typhi and Paratyphi A) from blood isolates in Nepal: surveillance of resistance and a search for newer alternatives. Int J Infect Dis 10, 434438.

Saha, S. K., Talukder, S. Y., Islam, M. \& Saha, S. (1999). A highly ceftriaxone resistant Salmonella typhi in Bangladesh. Pediatr Infect Dis $J$ 18, 387.

Sorbera, L. A., Del Fresno, N., Castaner, R. M. \& Rabasseda, X. (2002). Faropenem daloxate. Drugs Fut 27, 223.

Sun, H. Y., Tseng, S. P., Hsueh, P. R., Hung, C. C., Hsieh, S. M., Teng, L. J. \& Ho, S. W. (2005). Occurrence of ceftriaxone resistance in ciprofloxacin-resistant Salmonella enterica serotype Choleraesuis isolates causing recurrent infection. Clin Infect Dis 40, 208-209.

Weill, F. X., Guesnier, F., Guibert, V., Timinouni, M., Demartin, M., Polomack, L. \& Grimont, P. A. D. (2006). Multidrug resistance in Salmonella enterica serotype Typhimurium from humans in France (1993 to 2003). J Clin Microbiol 44, 700-708. 